\title{
Sarcopenia in metastatic cancer patients: results of a prospective non-randomized study.
}

Jonas DUBU ( $\nabla$ j.dubu@i-l-c.fr)

ILC Centre Jean Bernard / Elsan clinique Victor Hugo https://orcid.org/0000-0001-9662-7171

Anne-Lise SEPTANS

ILC/Weprom

Julien DOMONT

ILC Centre Jean Bernard/Elsan Clinique Victor Hugo

Hugues BOURGEOIS

ILC Centre Jean Bernard/Elsan Clinique Victor Hugo

Olivier DUPUIS

ILC Centre Jean Bernard/Elsan Clinique Victor Hugo

Amandine RUFFIER

ILC Centre Jean Bernard/Elsan Clinique Victor Hugo

Eric VOOG

ILC Centre Jean Bernard/Elsan Clinique Victor Hugo

\section{Yoann POINTREAU}

ILC Centre Jean Bernard/Elsan Clinque Victor Hugo

\section{Sophie ROCHE}

ILC Centre Jean Bernard/Elsan Clinique Victor Hugo

\section{Lydie SERRE}

Radiology department, maine image santé

\section{Hassan RABI}

Radiology department, maine image santé

\section{Fabrice DENIS}

ILC Centre Jean Bernard/Elsan Clinique Victor Hugo

Katell LE DO

ILC Centre Jean Bernard/Elsan Clinique Victor Hugo

\section{Research Article}

Keywords: sarcopenia, cancer, palliative care

Posted Date: March 11th, 2021 
DOI: https://doi.org/10.21203/rs.3.rs-230850/v1

License: (c) (1) This work is licensed under a Creative Commons Attribution 4.0 International License. Read Full License 


\section{Abstract \\ Background}

Prognostic factors can impact the quality of life and overall survival in metastatic situations: sarcopenia and nutritional status disorders.

\section{Methods}

We conducted a non-interventional, observational prospective study during 3 consecutive months (SPACE trial, ClinicalTrials.gov identifier: NCT04714203). Performance status, lumbar skeletal muscle index (by CT scan), albumin, C-reactive protein, or LDH, were collected from medical records in the classic balance sheet at inclusion and then at 3 and 6 months after the day of inclusion.

\section{Results}

38 patients were included with a median age of 68 years old and 31 were evaluable for sarcopenia. $58.1 \%$ of patients with metastatic cancer were sarcopenic at the diagnosis and $61 \%$ at 6 months. At the inclusion, $87.5 \%$ of sarcopenic patients were men $(p<0.0002)$ and sarcopenia status was associated with lung localization $(p<0.0332)$ and non-operable cancer $(p<0.0069)$.

\section{Conclusion}

The majority of patients in our study were sarcopenic at the inclusion and at 6 months. However, the number of patients was too small to correlate sarcopenia with survival. Further larger studies are needed to establish stronger results. In the future, sarcopenic patients could benefit from specialized care with nutrition and adapted physical activity.

\section{Introduction}

Cancer is one of the leading causes of death in the world and despite a great deal of progress in disease detection and treatment, cancer incidence is steadily increasing and particularly in certain localizations like pancreas, lung, brain and stomach [1,2]. Metastatic cancer is rarely curable with the exception of germ cell tumors $[3,4]$. Palliative care support is then most often offered. The recurring symptoms reported by patients are: pain, fatigue, decreased appetite, nausea, and are directly related to phenomena such as cachexia, loss of autonomy and deterioration of psychological state, resulting in decreased overall survival [5]. Chemotherapies and targeted therapies can provide a benefit in quality of life and survival only in the early phase [6]. Other prognostic factors can impact the quality of life and overall survival in these situations: sarcopenia and nutritional status disorders. 
Sarcopenia is defined by a loss of skeletal muscle mass and muscle function (strength and/or physical performance). The European Working Group on Sarcopenia in Older People described the diagnostic criteria in 2010 [7]. It was first defined for elderly people then for cancer patients, with a negative prognostic impact on overall survival $[8-10,11-15,16]$.

Skeletal muscle mass is usually assessed by CT scan: the L3 level (cross section facing the 3rd lumbar vertebra) was chosen as a reference because it reflects to the quantities of tissue in the whole body. The lumbar muscle mass area (paravertebral muscles, psoas, muscles of the abdominal wall) is divided by body height $\left(\mathrm{cm}^{2} / \mathrm{m}^{2}\right)$ to define the Lumbar Skeletal Muscle Index (LSMI) of each patient $[17,18]$.

Strength and performance are assessed by clinical tests: handgrip test for strength and Short Physical Performance Battery for performance (SPPB) (balance, walking speed, 5 time sit-to-stand tests) $[19,20]$.

Three categories are described to evaluate the severity [7]:

- Pre sarcopenia: a loss of muscle mass index is only detected,

- Sarcopenia: loss of muscle mass and strength or performance,

- Severe sarcopenia: significant decrease of mass, strength and performance

Sarcopenia is present in 10 to $70 \%$ of cancer patients and depends on the stage of the disease (localized or metastatic). It emerges as an unfavorable prognostic factor in overall survival and has been found correlated with a high comorbidity score, an increase in treatment-related complications and hospital costs [10, 21-25].

The Pronopall score has been validated in a prospective study [26], and also predicts survival according to 4 variables: Performance Status, number of metastatic sites, lactate deshydrogenase level (LDH) and albumin level [27].

We propose here to evaluate the prevalence of sarcopenia and its correlation with the Pronopall score in a prospective non-interventional study concerning cancer patients at the diagnosis of metastatic progression.

\section{Patients And Methods}

\section{Study Design and ethical considerations}

The SPACE study (ClinicalTrials.gov number, NCT04714203) is a prospective, non-interventional and single-center trial (Clinique Victor Hugo/ILC Jean Bernard, Le Mans). Patients were enrolled between June 1 and August 31, 2019 and provided informed consent. The authors collected the data in a secure excel file with anonymization. The study was conducted in accordance with the Declaration of Helsinki and the International Conference on Harmonisation Good Clinical Practice guidelines for biomedical research. Local ethic committee approved the manuscript. 


\section{Study population and inclusion criteria}

All patients were over 18 years old and suffered from metastatic cancer. Metastases were recently diagnosed (less than 3 months). The size of study population was determined by the inclusion period. Biological analysis and abdominal CT scan had to be performed less than 1 month before the inclusion.

\section{Exclusion criteria}

The exclusion criteria were: patients under 18, patients with germinal tumor, hematologic cancer, nonmetastatic cancer and pregnancy.

\section{Primary and secondary objectives}

The primary objective was to determine the prevalence of sarcopenia in cancer patients in an early metastatic situation.

The secondary objectives were the prevalence of undernutrition, overall survival, progression-free survival (PFS), event-free survival (EFS), and the correlation between the Pronopall score and sarcopenia.

\section{Sarcopenia measurement method}

The CT scans with abdominal sections were performed to assess muscle area (including psoas, rectus abdominus, obliques, erector spinae and quadratus lumborum muscles) at the level of third lumbar vertebrae on a slice showing both transversal processes of the vertebrae. To calculate the cross section of the tissue (cm2), the area of the muscle tissue was chosen according to the CT Hounsfield unit (HU), ranging from 29 to 150 for skeletal muscles; this area was divided to body height to calculate the lumbar L3 skeletal muscle index (LSMI). The IMAGEJ software was chosen for the validation of the volumes [18].

In our study, patients with a LSMI $<55.8 \mathrm{~cm}^{2} / \mathrm{m}^{2}$ for men and $<38.9 \mathrm{~cm}^{2} / \mathrm{m}^{2}$ for women will be considered sarcopenic [17] (Fig. 1).

LSMI assessment was performed by one trained investigator at the inclusion, and then at 3 and 6 months after inclusion.

\section{Biological analysis}

Albumin and LDH levels were recorded for nutritional status assessment and Pronopall score calculation.

\section{Nutritional status}

Criteria used to diagnose undernutrition were: a loss of at least $10 \%$ of weight in 6 months, a body mass index under 21 and an albuminemia level under $35 \mathrm{~g} / \mathrm{L}$, according to HAS guidelines [29].

\section{Data and statistical analysis}

The search for correlation with clinical and biological data reflecting the nutritional status and the aggressiveness of the disease was carried out, studying data are as follows: 
- body mass index,

- percentage of weight loss within 6 months (if available),

- plasma albumin level,

- level of C-Reactive Protein,

- LDH level,

- Pronopall score.

Qualitative data were compared using either the Chi-square or the Fischer Exact test and presented as percentages.

The time-to-event analyses were performed using the Kaplan-Meier method and the estimates were presented as rates with the corresponding $95 \% \mathrm{Cls}$.

Correlation between LSMI and Pronopall score was done with the non-parametric Spearman correlation test.

All the analyses were performed using SAS $\rightarrow 9.3$ (SAS Institute Inc. Cary, NC, USA).

\section{Results}

\section{Patient characteristics}

Thirty-eight patients were included in the study. Seven were non evaluable at inclusion for LSMI (5 CT scans were performed in an other center and data were not available and 2 patients had a thoracic CT scan without lumbar sections). Fifty-four point eight percent $(54,8 \%)$ of patients were male and median age was 66 years old. The main tumor locations were lung (25,9\%), colon (22,7\%) and breast (13\%). At inclusion, thirty-two patients had synchronous metastatic disease, and for the 6 other patients, metastatic progression occurred 4 months to 9 years after the initial diagnosis of cancer.

Thirty-seven of the thirty-eight patients $(97 \%)$ received a treatment for metastatic disease and $16 \%$ were included in a clinical trial. The characteristics are summarized in Table 1. 
Table 1

patient characteristics

\begin{tabular}{|ll|}
\hline Patient characteristics & \\
\hline Patients & $\mathrm{n}=31(\%)$ \\
\hline Median follow up (months) & $5,9(1,2 ; 8,8)$ \\
\hline Sex & \\
\hline Male & $17(54,8)$ \\
\hline Female & $14(45,2)$ \\
\hline Median age & $66,8(47,7-86,5)$ \\
\hline Performans status & \\
\hline 0 & $1(3,2)$ \\
\hline 1 & $12(38,7)$ \\
\hline 2 & $14(45,2)$ \\
\hline 3 & $4(12,9)$ \\
\hline Cancer location & \\
\hline Colorectal & $7(22,5)$ \\
\hline Stomach & $13(4,2)$ \\
\hline Ovarian & $2(29)$ \\
\hline Pancreas & $2(6,4)$ \\
\hline Lung & $2(6,4)$ \\
\hline Kidney & $8(25,8)$ \\
\hline Breath & $2(6,4)$ \\
\hline Bladder & \\
\hline Esophagus & \\
\hline Other & \\
\hline Number of metastasic sites & \\
\hline 1 & \\
\hline Surgery & \\
\hline
\end{tabular}




\begin{tabular}{|ll|}
\hline Patient characteristics & \\
\hline Chemotherapy & $24(77,4)$ \\
\hline Number of chemo lines & \\
\hline 0 & $7(22,5)$ \\
\hline 1 & $14(45,2)$ \\
2 and more & $10(32,2)$ \\
\hline Targeted therapy & $9(29)$ \\
\hline Radiotherapy & $9(29)$ \\
\hline Hormonotherapy & $3(9,7)$ \\
\hline Inclusion in a clinical trial & $5(16,1)$ \\
\hline
\end{tabular}

\section{Sarcopenia}

LSMI was assessed at inclusion for 31 patients, at 3 months for 18 patients (8 deaths, 12 missing data), and at 6 months for 13 patients (10 deaths, 15 missing data). Sarcopenia was confirmed at inclusion for $51,6 \%$ of patients, for $61,1 \%$ at 3 months and for $61,5 \%$ at 6 months. Male gender and a recent surgical treatment were significantly favoring factors $(p<0.01)$ (Table 2$)$. 
Table 2

Patient characteristics according to muscle mass index

\begin{tabular}{|c|c|c|c|}
\hline & non-sarcopenic group & sarcopenic group & p-value \\
\hline Patients & $n=15(\%)$ & $\mathrm{n}=16(\%)$ & \\
\hline Age & $68,1(53,1-86,1)$ & $66,5(47,7-81,2)$ & 0,6811 \\
\hline Sex & & & 0,0002 \\
\hline Male & $3(20)$ & $14(87,5)$ & \\
\hline Female & $12(80)$ & $2(12,5)$ & \\
\hline Performans status & & & 0,2188 \\
\hline 0 & $1(6,7)$ & 0 & \\
\hline 1 & $4(26,6)$ & $8(50)$ & \\
\hline 2 & $9(60)$ & $5(31,2)$ & \\
\hline 3 & $1(6,7)$ & $3(18,8)$ & \\
\hline Tumoral location & & & 0,0332 \\
\hline Breath & $4(30,7)$ & 0 & \\
\hline Colorectal & $3(23,1)$ & $4(26,7)$ & \\
\hline Lung & $1(7,7)$ & $7(46,6)$ & \\
\hline Other & $5538,5)$ & $4(26,7)$ & \\
\hline Number of metastasis & & & 0,7043 \\
\hline$<1$ & $5(33,3)$ & $4(25)$ & \\
\hline $2 \geq$ & $10(66,7)$ & $12(75)$ & \\
\hline \multicolumn{4}{|l|}{ Treatment at inclusion } \\
\hline Surgery & & & 0,0069 \\
\hline Yes & $5(33,3)$ & $13(81,3)$ & \\
\hline No & $10(66,7)$ & $3(18,7)$ & \\
\hline Number of chemo-lines & & & 0,6513 \\
\hline 0 & $2(13,3)$ & $4(25)$ & \\
\hline 1 & $7(46,7)$ & $8(50)$ & \\
\hline 2 & $6(40)$ & $4(25)$ & \\
\hline
\end{tabular}


The prevalence of sarcopenia in the study population is $58,1 \%$.

\section{Undernutrition}

Body mass index was under 21 for $19 \%$ of patients (31 evaluable patients) at inclusion, $33 \%$ at 3 months (21 patients) and $41,7 \%$ at 6 months (12 patients).

Albumin level was under $35 \mathrm{~g} / \mathrm{L}$ for $47 \%$ of patients (34 evaluable patients), $60 \%$ at 3 months (20 patients) and $57 \%$ at 6 months (7 patients).

Twelve patients were evaluable for weight loss and only one had a $15 \%$ weight loss since the inclusion.

\section{Survival}

Median overall survival of the study population is 7,5 months ( $95 \%$ Cl: 5.5 to 8.8$)$ (Supplementary Fig. 2).

There was no difference between the sarcopenic group and the non-sarcopenic group: 7,1 months for the sarcopenic group ( $95 \% \mathrm{Cl}: 3,9$ to 8,8$)$ versus 8,3 months for the non-sarcopenic group $(95 \% \mathrm{Cl}: 3,9$ to 8,8$)$ $(p=0,6585)$ (Fig. 3).

Median progression free survival of the study population was 7,5 months without any difference between the two groups of patients ( 7,1 months for the sarcopenic group $(95 \% \mathrm{Cl}: 3,4$; not reached) versus 7,5 months for the non-sarcopenic group (95\%Cl: 3,4; not reached)) $(p=0,4560)$ (Fig. 4).

Twelve (38,7\%) patients died during the study: 7 within 3 months of inclusion, 2 within 6 months and 3 after 6 months. The cause of death was progression.

\section{Pronopall score}

According to the pronopall score, the study population was divided in 3 prognostic groups: good $(0-3$ score), intermediate group (4-7 score) and bad (8-10 score) (Table 3).

Table 3

Pronopall Score

\begin{tabular}{|lll|}
\hline & non-sarcopenic group & sarcopenic group \\
\hline Patients & $n=10(\%)$ & $n=15(\%)$ \\
\hline Pronopall Score & & \\
\hline $0-3$ & $4(40)$ & $6(40)$ \\
\hline 4 to 7 & $5(50)$ & $6(40)$ \\
\hline 8 and more & $1(10)$ & $3(20)$ \\
\hline
\end{tabular}


Ninety percent of patients had a good or intermediate score in the non-sarcopenic group and $80 \%$ in the sarcopenic group. According to the Spearman coefficient, there was no significant correlation between Pronopall score and sarcopenia at inclusion (rho $=0.1751 ; p=0.3951)$, at 3 months (rho $=0.009 ; p=$ 0.9697 ) and at 6 months (rho $=0.210 ; p=0.5348)$.

\section{Discussion}

Nowadays, the evaluation of sarcopenia by CT scan at L3 vertebrae in palliative patients is still too scarce despite it's a reference method. Sarcopenia is often underestimated although it is clearly associated with older age, co-morbidities, increased infectious complications and early mortality.

Sarcopenia was diagnosed in $58 \%$ of our study population. Median overall survival was 7,5 months without any significant difference between sarcopenic and non-sarcopenic group nor correlation with Pronopall Score.

Interpretation of the results is limited by the size of the study sample and missing data (noninterventional study). A prospective study published in 2019 on 334 patients with advanced solid tumors (66\% metastatic disease) has shown a significant correlation between survival and sarcopenia in palliative situation [30]. Yet they used only clinical tool to evaluate sarcopenia. Perhaps future research on detection of sarcopenia in palliative situation would consider clinical tools with CT scan data as an optimal solution.

The treatment of sarcopenia is currently limited to physical exercise and sufficient protein intake [31-34]. Because of the high prevalence in this target population, a prospective larger interventional study combining sarcopenia screening and specific care (nutritional support and adapted physical activity) is warranted in order to assess its impact on the quality of life and overall survival of these patients. The search for correlation with clinical and biological data reflecting the nutritional status and the aggressiveness of the disease will be carried out in a larger population.

\section{Declarations}

Funding: Partial financial support was received from Elsan SAS group, France.

Conflicts of interest/Competing interests: The authors have no conflicts of interest to declare that are relevant to the content of this article.

\section{Availability of data and material: N/A}

Code availability: ImageJ Version 1.2.4 RRID:SCR_003070 ; SAS® 9.3 (SAS Institute Inc. Cary, NC, USA).

Authors' contributions: All authors contributed to the study conception and design. All authors read and approved the final manuscript. 
Ethics approval: All procedures performed in studies involving human participants were in accordance with the ethical standards of the institutional and/or national research committee and with the 1964 Helsinki Declaration and its later amendments or comparable ethical standards.

Consent to participate: Informed consent was obtained from all individual participants included in the study.

\section{Consent for publication: N/A}

\section{Acknowledgements}

We thank Magali Balavoine (data manager), Anne-Lise Septans (biostatistician), Lydie Serre (radiology technician) and ELSAN group for their support.

\section{References}

1. Fitzmaurice C, Allen C, Barber RM, Barregard L, Bhutta ZA et al. Global, regional, and national cancer incidence, mortality, years of life lost, years lived with disability, and disability-adjusted life-years for 32 cancer groups, 1990 to 2015 : a systematic analysis for the global burden of disease study. JAMA Oncol 2017 Apr 1; 3 (4): 524-548.

2. Siegel R, Naischadham D, Jemal A. Cancer statistics, 2013. CA Cancer J Clin 2013 Jan; 63(1): 11-30.

3. Prigerson HG, Bao Y, Shah MA, Paulk ME, LeBlanc TW et al. Chemotherapy use, performance status, and quality of life at the end of life. JAMA Oncol 2015 Sep; 1(6): 778-84.

4. Quaresma M, Coleman MP, Rachet B. 40-years trends in an index of survival for all cancers combined and survival adjusted for age and sex for each cancer in England and Wales, 1971-2011: a population-based study. Lancet 2015 Mar 28; 385(9974): 1206-18.

5. Trajkovic-Vidakovic M, de Graeff A, Voest EE, Teunissen SC. Symptoms tell it all : a systematic review of the value of symptom assessment to predict survival in advanced cancer patients. Crit Rev Oncol Hematol 2012 Oct; 84(1): 130-48.

6. Hiu D, Hannon BL, Zimmermann C, Bruera E. Improving patient and caregiver outcomes in oncology: team-based, timely and targeted palliative care. CA Cancer J Clin 2018 Sep; 68(5): 356-376.

7. Cruz-Jentoft AJ, Baeyens JP, Bauer JM, Boirie Y, Cederholm T et al. Sarcopenia: european consensus on definition and diagnosis: report of the European Working Group on Sarcopenia in Older People. Age and Ageing $2010 \mathrm{Jul} ; 39$ (4): 412-23.

8. Kim TN, Choi KM. Sarcopenia: definition, epidemiology, and pathophysiology. J Bone Metab, 2013 May; 20(1): 1-10.

9. Bravo-José P, Moreno E, Espert M, Romeur M, Martinez P et al. Prevalence of sarcopenia and associated factors in institutionalised older adult patients. Clin Nutr ESPEN, 2018 Oct; 27: 113-119.

10. Stephens NA, Skipworth RJ, Fearon KC. Cachexia, survival and the acute phase response. Curr Opin Support Palliat Care. 2008 Dec; 2(4): 267-74. 
11. Tisdale MJ. Mechanisms of cancer cachexia. Physiol Rev 2009 Apr; 89(2): 381-410.

12. Argiles J, Lopezsoriano F. Cancer Cachexia. Int J Oncol 1997 Mar; 10(3): 565-72.

13. GewandterJS, Dale W, Magnuson A, Pandya C, Heckler CE et al. Associations between a patientreported outcome (PRO) measure of sarcopenia and falls, functional status, and physical performance in older patients with cancer. J Geriatr Oncol 2015 Nov; 6(6): 433-41.

14. Janssen I, Heymsfield SB, Ross R. Low relative skeletal muscle mass (sarcopenia) in older persons is associated with functional impairment and physical disability. J Am Geriatr Soc 2002 May; 50(5): 889-96.

15. Velikova G, Wright P, Smith AB, Stark D, Perren T et al. Self-reported quality of life of individual cancer patients: concordance of results with disease course and medical records. J Clin Oncol 2001 Apr 1; 19(7): 2064-73.

16. Pérez Camargo DA, Allende Pérez SR, Verastegui Avilés E, Rivera Franco MM, Meneses Garcia et al. Assessment and impact of phase angle and sarcopenia in palliative cancer patients. Nutr Cancer 2017 Nov-Dec; 69 (8): 1227-1233.

17. Lanic H, Kraut-tauzia J, Modzelewski R, et al. Sarcopenia is an independent prognostic factor in elderly patients with diffuse large B-cell lymphoma treated with immunochemotherapy. Leuk Lymphoma 2014; 55:817-823.

18. Teigen LM, Kuchnia AJ, Nagel E, Deuth C, Vock et al. Impact of software selection and ImageJ tutorial corrigendum on skeletal muscle measures at the third lumbar vertebra on computed tomography scans in clinical populations. JPEN J Parenter Enteral Nutr 2018 Jul; 42(5): 933-42.

19. Guralnik JM, Seeman TE, Tinetti ME, Nevitt MC, Berkman LF. Validation and use of performance measures of functioning in a non-disabled older population: MacArthur studies of successful aging. Anging (Milano) 1994 Dec, 6 (6): 410-9.

20. Guralnik JM, Ferrucci L, Pieper CF, et al. Lower extremity function and subsequent disability: consistency across studies, predictive models, and value of gait speed alone compared with the short physical performance battery. J Gerontol A Biol Sci Med Sci. 2000; 55:M221-31.

21. Shachar SS, Williams GR. The obesity paradox in cancer-moving beyond BMI-reponse. Cancer Epidemiol Biomarkers Prev 2017 Jun; 26(6): 981.

22. Prado CM, Lieffers JR, McCargar LJ, Reiman T, Sawyer MB. Prevalence and clinical implications of sarcopenic obesity in patients with solid tumours of the respiratory and gastrointestinal tracts: a population-based study. Lancet Oncol 2008 Jul; 9(7): 629-35.

23. Janssen I, Shepard DS, Katzmarzyk PT, Roubenoff R. The healthcare costs of sarcopenia in the United States. J Am Geriatr Soc. 2004 Jan; 52(1): 80-5.

24. Nipp R, Fuchs G, El-Jawahri A, Mario J, Troschel F et al. Sarcopenia is associated with quality of life and depression in advanced cancer. The Oncologist 2018; 23: 97-104.

25. Shachar SS, Deal AM, Weiberg M, Nyrop KA, Williams GR et al. Skeletal muscle measures as predictor of toxicity, hospitalization, and survival in patients with metastatic breast cancer receiving taxane-based chemotherapy. Clin Cancer Res 2017 Feb 1; 23(3): 658-665. 
26. Bourgeois H, Grudé F, Solal-Céligny P, Dupuis O, Voog E et al. Clinical validation of a prognostic tool in a population of outpatients treated for incurable cancer undergoing anticancer therapy: PRONOPALL study. Ann Oncol 2017 Jul; 28(7): 1612-1617.

27. Aung A, Alqudihy S, Rybicki L, Platt A, Davis MP. Does serum albumin and creatinine predict survival of inpatient palliative care patients? Am J Hosp Palliat Care 2014 Dec; 31(8): 862-6.

28. Lee JS, Kim YS, Kim EY, Jin W. Prognostic significance of CT-determined sarcopenia in patients with advanced gastric cancer. PLoS One 2018 Aug 20; 13(8): e0202700.

29. HAS, Synthèse des recommandations professionnelles (avril 2007) : stratégie de prise en charge en cas de dénutrition protéino-énergétique chez les personnes âgées.

30. Da Silva JR, Wiegert EVM, Oliveira L, Calixto-Lima L. Different methods for diagnosis of sarcopenia and its association with nutritional status and survival in patients with advanced cancer in palliative care. Nutrition, 2019 Apr; 60: 48-52.

31. Dhillon JS R, Hasni S. Pathogenesis and Management of Sarcopenia. Clin Geriatr Med 2017 Feb; 33(1): 17-26.

32. Zhou CJ, Zhang FM, Zhang FY, Yu Z, Chen XL, Shen X, et al. Sarcopenia: a new predictor of postoperative complications for elderly gastric cancer patients who underwent radical gastrectomy. $J$ Surg Res 2017; 211:137-46.

33. Smith LA, O'Flanagan CH, Bowers LW, Allott, Hursting SD. Translating mechanism-based strategies to break the obesity-cancer link: a narrative review. J Aca Nutr Diet 108 Apr: 118 (4): 652-667.

34. Moore SA, Hrisos N, Errington L, Rochester L, Rodgers H, Witham M, Sayer AA. Exercise as a treatment for sarcopenia: an umbrella review of systematic review evidence. Physiotherapy 2020; 107:189-201.

\section{Figures}




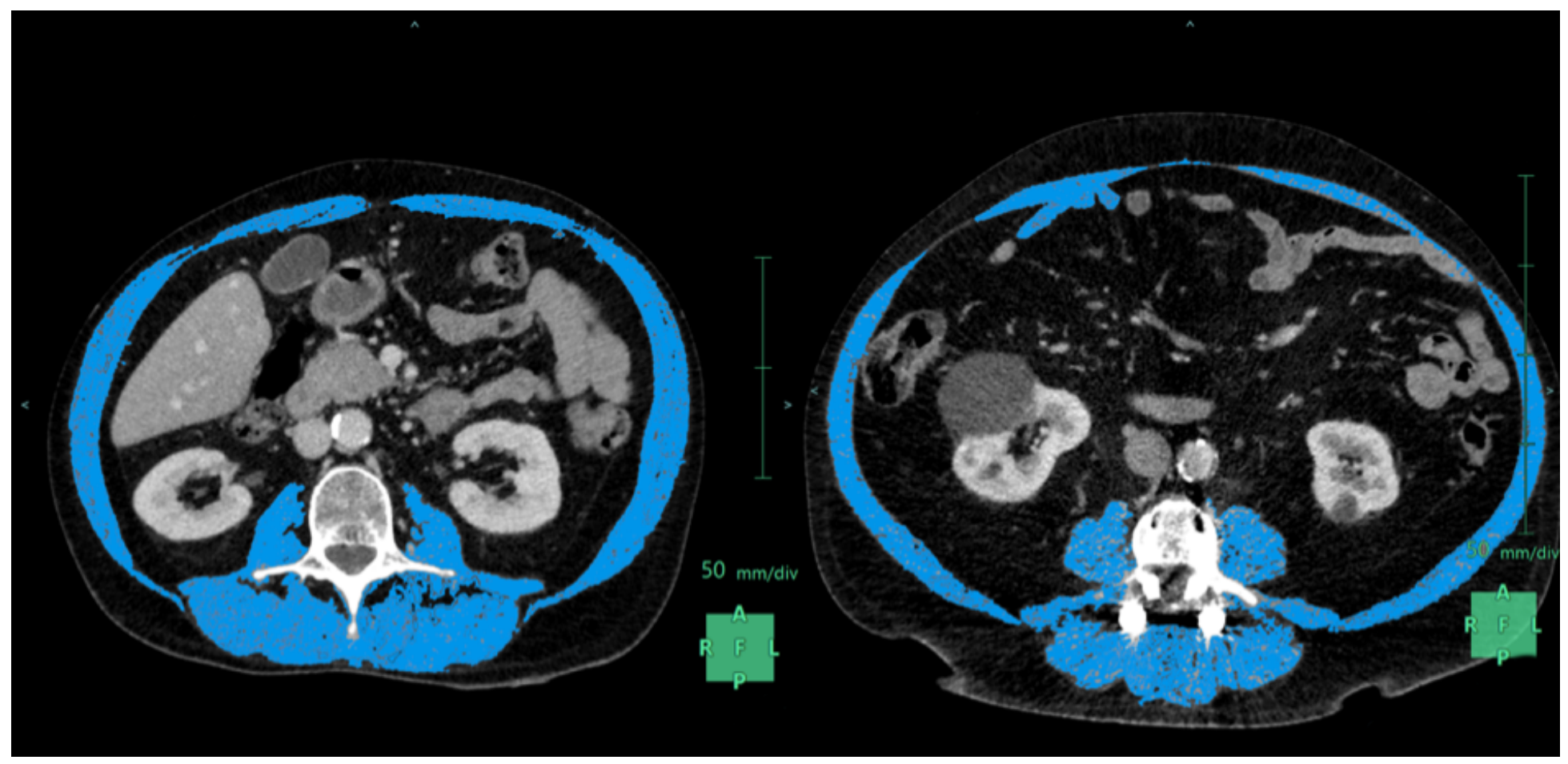

\section{Figure 1}

example of abdominal L3 CT scan (muscle in blue): normal mass (on the left) vs sarcopenic patient (on the right) for 2 male patients with same BMI

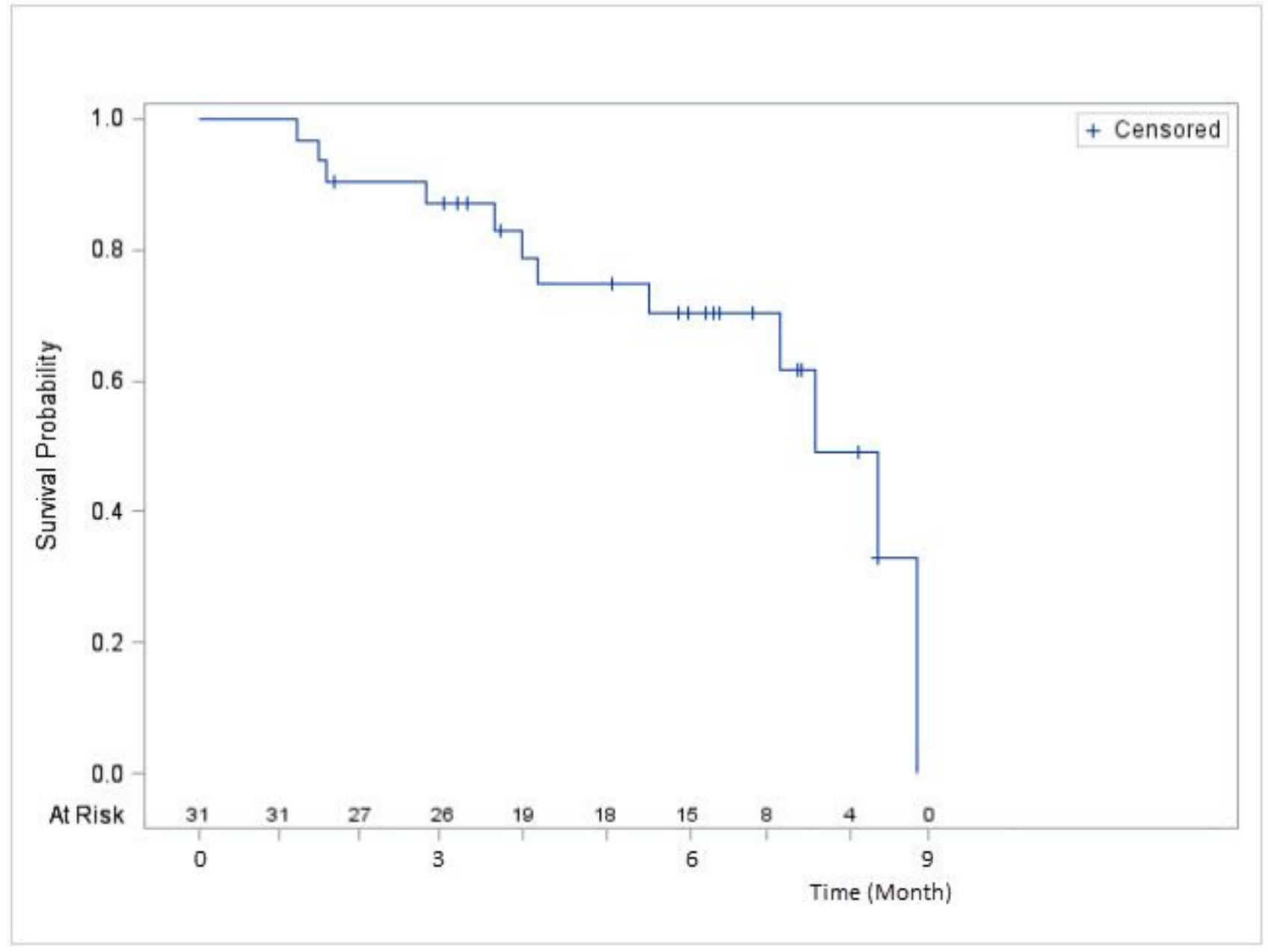


Figure 2

Overall survival

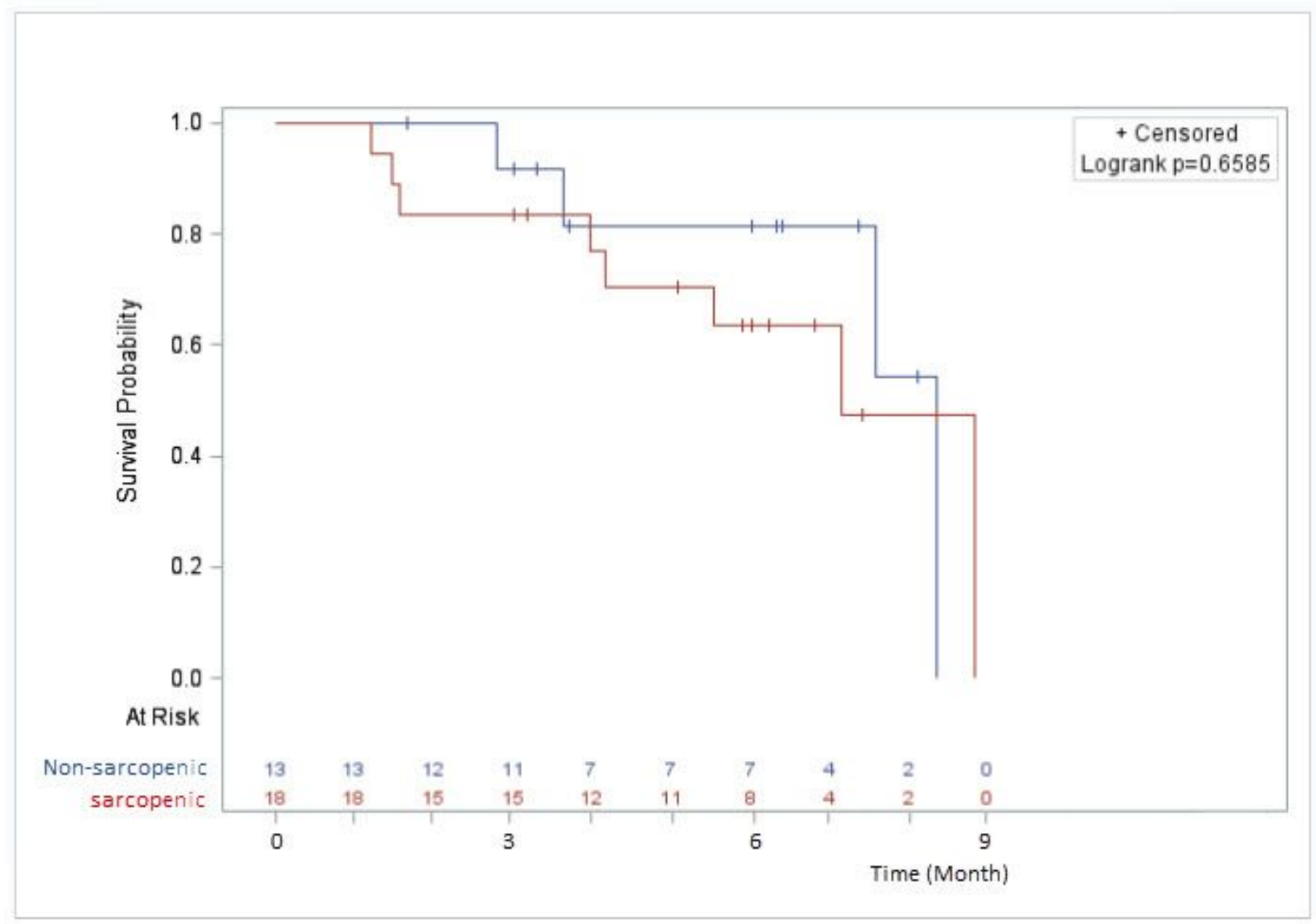

Figure 3

Overall survival between sarcopenic and non-sarcopenic group 


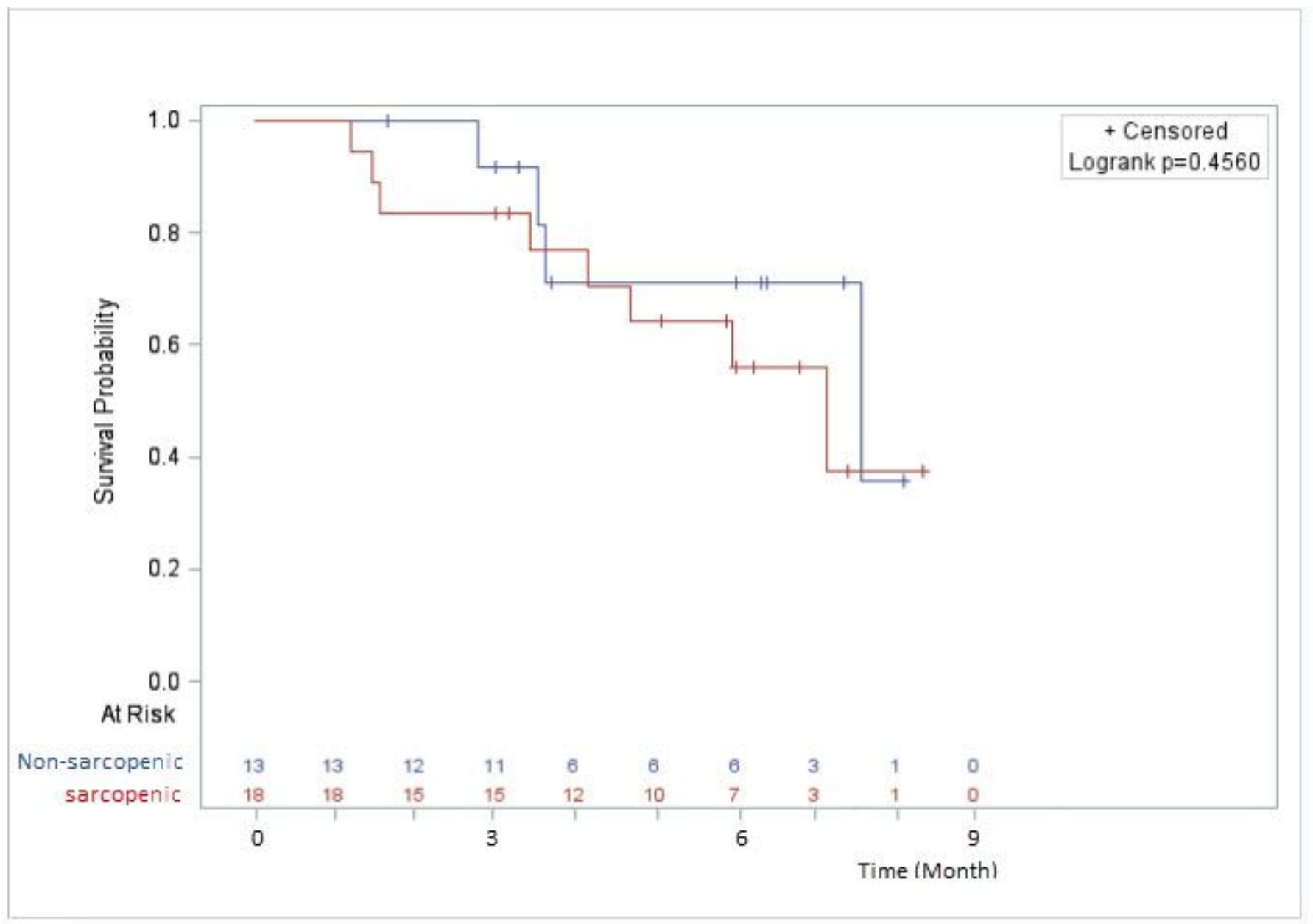

\section{Figure 4}

Progression free survival between sarcopenic and non-sarcopenic group

\section{Supplementary Files}

This is a list of supplementary files associated with this preprint. Click to download.

- JSCCSupplementaryFigure2.docx 